\title{
Regulação do metabolismo de glicose e ácido graxo no músculo esquelético durante exercício físico
}

\author{
Regulation of glucose and fatty acid metabolism \\ in skeletal muscle during contraction
}

Leonardo R. Silveira' ${ }^{1,2}$, Carlos Hermano da Justa Pinheiro3, Claudio C. Zoppi ${ }^{4}$, Sandro M. Hirabara ${ }^{5}$, Kaio F. Vitzel ${ }^{3}$, Reinaldo A. Bassit ${ }^{3}$, Carol G. Leandro', Marina R. Barbosa', Igor H. Sampaio'2, Iracema H. P. Melo', Jarlei Fiamoncini ${ }^{3}$, Everardo M. Carneiro ${ }^{4}$, Rui Curi ${ }^{3}$

\section{SUMÁRIO}

O ciclo glicose-ácido graxo explica a preferência do tecido muscular pelos ácidos graxos durante atividade moderada de longa duração. Em contraste, durante o exercício de alta intensidade, há aumento na disponibilidade e na taxa de oxidação de glicose. A produção de espécies reativas de oxigênio (EROs) durante a atividade muscular sugere que o balanço redox intracelular é importante na regulação do metabolismo de lipídios/carboidratos. As EROs diminuem a atividade do ciclo de Krebs e aumentam a atividade da proteína desacopladora mitocondrial. $O$ efeito oposto é esperado durante a atividade moderada. Assim, as questões levantadas nesta revisão são: Por que o músculo esquelético utiliza preferencialmente os lipídios no estado basal e de atividade moderada? Por que o ciclo glicose-ácido graxo falha em exercer seus efeitos durante o exercício intenso? Como o músculo esquelético regula o metabolismo de lipídios e carboidratos em regime envolvendo o ciclo contração-relaxamento. Arq Bras Endocrinol Metab. 2011;55(5):303-13

\section{Descritores}

Metabolismo mitocondrial; exercício prolongado; ciclo glicose-ácido graxo

\section{SUMMARY}

The glucose-fatty acid cycle explains the preference for fatty acid during moderate and long duration physical exercise. In contrast, there is a high glucose availability and oxidation rate in response to intense physical exercise. The reactive oxygen species (ROS) production during physical exercise suggests that the redox balance is important to regulate of lipids/carbohydrate metabolism. ROS reduces the activity of the Krebs cycle, and increases the activity of mitochondrial uncoupling proteins. The opposite effects happen during moderate physical activity. Thus, some issues is highlighted in the present review: Why does skeletal muscle prefer lipids in the basal and during moderate physical activity? Why does glucose-fatty acid fail to carry out their effects during intense physical exercise? How skeletal muscles regulate the lipids and carbohydrate metabolism during the contraction-relaxation cycle? Arq Bras Endocrinol Metab. 2011;55(5):303-13

\section{Keywords}

Departamento de Bioquímica e Imunologia, Faculdade de Medicina de Ribeirão Preto (FMRP-USP),

Ribeirão Preto, SP, Brasil ${ }^{2}$ Escola de Educação Física e Esporte de Ribeirão Preto, USP, Ribeirão Preto, SP, Brasil

${ }^{3}$ Departamento de Fisiologia e Biofísica, Instituto de Ciências Biomédicas, Universidade de São Paulo (ICB-USP), São Paulo, SP, Brasil

${ }^{4}$ Departamento de Anatomia, Biologia Celular, Fisiologia e

Biofísica, Instituto de Biologia, Universidade Estadual de Campinas (Unicamp), Campinas, SP, Brasil ${ }^{5}$ Faculdade de Educação Física, Universidade Cruzeiro do Sul (Unicsul), São Paulo, SP, Brasil ${ }^{6}$ Núcleo de Educação Física e Ciências do Esporte, Centro Acadêmico de Vitória (CAV), Universidade Federal de Pernambuco (UFPE), Recife, PE, Brasil

Correspondence to: Leonardo R. Silveira Escola de Educação Física e Esporte de Ribeirão Preto, Universidade de São Paulo Av. Bandeirantes, 3900, - 14040-901, Ribeirão Preto, RS, Brasil Irs@icb.usp.br

Recebido em 17/Jan/2011 Aceito em 12/Maio/2011

\section{INTRODUÇÃO}

$\mathrm{H}$ á 40 anos, Randle e cols. (1) propuseram a existência de uma competição entre glicose e ácidos graxos (AG) como substratos para a síntese de ATP no músculo esquelético, cardíaco e adipócitos. Nesse processo, foi demonstrado que, sob elevada disponibilidade de lipídios, os músculos esqueléticos utilizam predominantemente AG para a síntese e obtenção de ATP. Em contraste, sob elevada disponibilidade de carboidratos, utilizam predominantemente glicose. A questão que surge é qual a importância fisiológica dessa regulação entre glicose e ácidos graxos? Podemos encontrar uma respos- 
ta para essa pergunta entendendo a utilização de glicose e ácidos graxos como um processo evolutivo do homem para sobreviver e se adaptar em condições de escassez de alimento. Os carboidratos constituem uma valiosa fonte de energia ao nosso organismo. Porém, a capacidade de estoque desse valioso substrato é limitada, fazendo-se necessária a busca por estratégias de economia e armazenamento de energia na forma de carboidrato. O requerimento diário de glicose por esses tecidos é da ordem de $300 \mathrm{~g} /$ dia, ao passo que a capacidade do fígado, principal reservatório de carboidratos, em armazenar glicogênio é de cerca de $100 \mathrm{~g} /$ dia em adultos (2). Por outro lado, as reservas de lipídios em nosso organismo são inúmeras vezes superiores àquelas de carboidratos, o que explicaria a preferência do nosso organismo pelos lipídios em condições basais e principalmente de jejum, aumentando a disponibilidade de glicose para outros tecidos (sistema nervoso, sanguíneo e imunológico), os quais são essencialmente mantidos à custa desse substrato (3). A importância fisiológica desse mecanismo conhecido como ciclo glicose-ácido graxo, portanto, consiste não somente no aumento do fornecimento de energia aos tecidos, mas principalmente na economia da utilização dos estoques limitados de glicose.

Esse conceito ajuda a esclarecer a preferência do tecido muscular pelos ácidos graxos durante atividade moderada mantida por longo período. Nessas condições, a lipólise do tecido adiposo periférico é favorecida aumentando a disponibilidade de ácidos graxos para a captação e utilização pelo músculo esquelético. Caso essa regulação não ocorra, os estoques de glicogênio podem ser depletados precocemente, comprometendo a performance muscular $(4,5)$. Em contraste, durante o exercício de alta intensidade mantido por curto intervalo de tempo, há aumento na disponibilidade e na taxa de oxidação de glicose, seguido de redução na disponibilidade e na taxa de oxidação de lipídios (6). As observações acima sugerem que, durante contrações de intensidade leve para moderada, os ácidos graxos são mobilizados do tecido adiposo (periférico e intramuscular) através da lipólise e utilizados pelo músculo esquelético. Durante o exercício de alta intensidade, a liberação dos AG do tecido adiposo é marcadamente diminuída, seguida por elevação na disponibilidade e na oxidação de glicose (7). Embora esteja bem estabelecida, pelo ciclo glicose-ácido graxo, a predominância dos lipídios durante o exercício leve/ moderado e dos carboidratos durante o exercício intenso, ainda é pouco conhecido o mecanismo que regula a preferência desses dois substratos durante a contração muscular. Evidência de produção elevada de espécies reativas de oxigênio (EROs) durante a atividade muscular intensa (8) sugere que o balanço redox intracelular pode exercer papel importante na regulação do metabolismo de lipídios/carboidratos durante o exercício. Em concentração intracelular elevada, as EROs diminuem a atividade do ciclo de Krebs, favorecendo o metabolismo de carboidratos $(9,10)$. Nessa condição, há aumento da atividade da proteína desacopladora mitocondrial (UCP3) (6). O efeito oposto é esperado durante a atividade moderada, quando a oxidação de ácidos graxos é predominante. Portanto, as principais questões levantadas nessa revisão são: a) Por que o músculo esquelético utiliza preferencialmente os lipídios em relação aos carboidratos no estado basal e de atividade leve a moderada? b) Por que o ciclo glicose-ácido graxo falha em exercer seus efeitos durante o exercício intenso? c) Como o músculo esquelético regula o metabolismo de lipídios e carboidratos durante contrações?

\section{O CICLO GLICOSE-ÁCIDO GRAXO DURANTE A ATIVIDADE MUSCULAR MODERADA}

Está bem estabelecido que os ácidos graxos e os carboidratos são os principais substratos para a produção de energia muscular (4-6). As principais vias metabólicas envolvidas nesse processo, glicólise, ciclo do ácido tricarboxílico (CAT) e $\beta$-oxidação oxidam glicose e ácidos graxos, gerando $\mathrm{NADH}$ e $\mathrm{FADH}_{2}$. Embora os aminoácidos também sejam oxidados nesse processo, sua contribuição é baixa comparada a dos carboidratos e ácidos graxos (11). Em acordo com a teoria quimiosmótica de Mitchell, os elétrons dessas moléculas são transportados através da cadeia respiratória, reduzindo a molécula de $\mathrm{O}_{2}$ a $\mathrm{H}_{2} \mathrm{O}$. A produção oxidativa de ATP está acoplada ao transporte de prótons da matriz mitocondrial para o espaço intermembrana, proporcionando a energia $\left(\Delta \mu \mathrm{H}^{+}\right)$necessária para a síntese oxidativa de ATP (12). Por outro lado, durante a produção de energia anaeróbia, a glicólise é a principal via de síntese de ATP, seguida do aumento da produção de lactato/ $\mathrm{H}^{+}$(11) (Figura 1). O processo de contração muscular é regulado de forma que a produção de energia é proporcional à demanda metabólica imposta pela atividade muscular. Porém, o sinal que regula a preferência do músculo esquelético por glicose ou ácidos graxos é complexo e pode ser determinado por diferentes fatores, incluindo dieta, nível de treinamento, intensidade e duração do exercício. Por exemplo, agudamente uma 
elevada disponibilidade de AG (dieta hiperlipídica) em sujeitos normais, durante o repouso, aumenta a oxidação de lipídios diminuindo a oxidação de carboidratos. O efeito oposto é observado quando a disponibilidade de carboidratos é aumentada (13).

Ao contrário das reservas de carboidratos, as reservas de lipídios em humanos são ilimitadas proporcionando maior eficiência na produção final de energia em comparação aos carboidratos. A densidade energética dos lipídios é aproximadamente 10 vezes maior a que dos carboidratos (i.e., $38 \mathrm{~kJ} . g$-1 vs $4.2 \mathrm{~kJ} . \mathrm{g}$-1), enquanto o peso relativo como estoque de energia é menor (3). Isso significa que, para estocarmos uma quantidade equivalente de energia fornecida pela gordura como glicogênio, o estoque de energia teria de ser cerca de 10 vezes mais pesado, o que seria crítico para a performance durante a contração muscular.

A eficiência dos ácidos graxos como substrato energético foi bem ilustrada em pássaros migratórios, os quais foram capazes de voar aproximadamente 1.500 milhas durante 60 h a 40,2 km/h. Análises de biópsia mostraram que os índices de massa adiposa nessas espécies diminuíram em aproximadamente sete vezes (de 4,0 para 0,6 U após o esforço) (11). Em humanos, estima-se que os estoques de triacilgliceróis são suficientes para sustentar a contração muscular moderada por

Meio extracelular

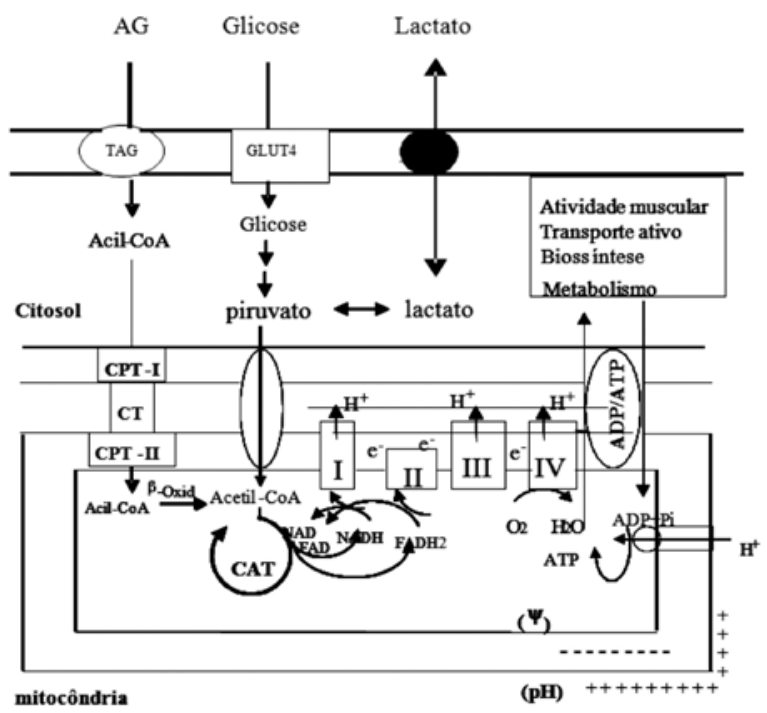

Figura 1. Metabolismo de glicose, de ácidos graxos e produção de energia no músculo esquelético. As abreviaturas são: AG: ácido graxo; TrAG: transportador de ácido graxo; Glut: transportador de glicose; CPT-I: carnitina palmitoiltransferase I; CPT-II: carnitina palmitoiltransferase II; CT: transportador de carnitina; $\beta$-oxid: $\beta$-oxidação; CAT: ciclo do ácido tricarboxílico. aproximadamente 120 h. Em contraste, para a mesma condição, os carboidratos são estimados para proporcionarem energia para contração muscular por somente 90 min de exercício (3), podendo alcançar valores um pouco mais elevados em atletas de resistência.

Os ácidos graxos oxidados no músculo esquelético durante o exercício são derivados principalmente dos triacilglicerídeos do tecido adiposo e dos depósitos intracelulares do tecido muscular (14). A lipólise nesses tecidos é regulada pela lipase sensível a hormônios, ativada pela estimulação beta-adrenérgica durante o exercício, particularmente pelas catecolaminas (15). Romijn e cols. (16) examinaram a contribuição dos lipídios na produção de energia durante 30 min de exercício a 25\%, 65\% e $85 \%$ do consumo máximo de $\mathrm{O}_{2}\left(\mathrm{VO}_{2 \operatorname{máx}}\right)$ em indivíduos treinados e em jejum. Foi demonstrado que a oxidação de lipídios aumenta em resposta à intensidade de exercício, alcançando o pico em aproximadamente $65 \% \mathrm{VO}_{2 \text { máx }}$ (Figura 2). Nessas condições, a quantidade absoluta de ácidos graxos oxidados aumenta na mesma proporção em que o tempo de exercício é elevado $(2,4,5)$. Esse aumento na oxidação dos ácidos graxos induz uma regulação no metabolismo de carboidrato, reduzindo a oxidação de glicose. Costill e cols. (17) foram os primeiros a demonstrar que, em comparação a indivíduos controles, a ingestão de lipídios combinada à administração de heparina (para liberação das lípases de lipoproteínas do endotélio), antes do exercício, elevou os níveis de ácidos graxos circulantes diminuindo a glicogenólise em aproximadamente $40 \%$ durante 30 min de corrida moderada. A oxidação elevada de ácidos graxos, portanto, pode substancialmente reduzir a utilização de carboidrato. Esse conceito foi proposto originalmente por Randle e cols. em 1963 e definido como ciclo glicose-ácido graxo (1). O mecanismo que suporta esse conceito está associado a uma razão elevada das concentrações de

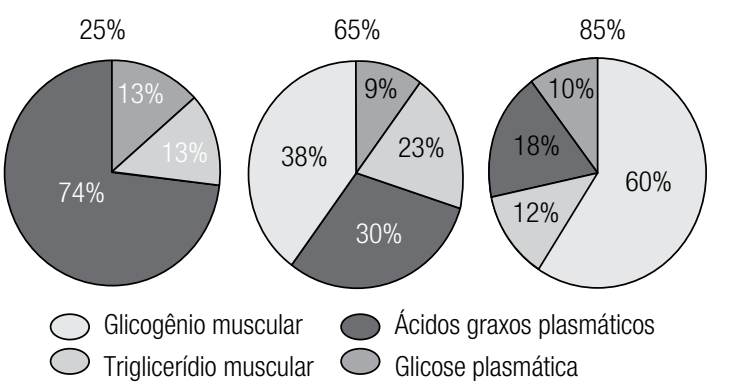

Figura 2. Efeito da intensidade $\left(\mathrm{VO}_{2 \max } \%\right)$ de exercício no consumo de glicose e ácidos graxos plasmáticos, glicogênio e triglicerídio muscular. Os valores (\%) são relativos ao consumo máximo de energia ( $\mathrm{J} / \mathrm{kg} / \mathrm{min})$. Modificado Romijn e cols. (16). 
acetil-CoA/CoA-SH como consequência de uma oxidação elevada de lipídios seguida por um aumento no conteúdo intracelular de citrato e glicose-6-P (G6-P). $\mathrm{O}$ acúmulo de acetil-CoA inibe a enzima piruvato desidrogenase (PDH), via ativação da $\mathrm{PDH}$ quinase, a enzima responsável pela fosforilação e inativação do complexo PDH, reduzindo a oferta de piruvato (glicose) como substrato oxidativo. De modo sinérgico, o conteúdo elevado de citrato inibe a enzima reguladora da via glicolítica fosfofrutoquinase (PFK). Esse efeito aumenta a razão G6-P/F1,6-bifosfato inibindo a hexoquinase, a enzima responsável pela captação e fosforilação de glicose, consequentemente reduzindo a disponibilidade intracelular de glicose como substrato (Figura 3). Apesar do papel central do citrato nesse processo, atualmente um grande número de estudos tem falhado em demonstrar esse efeito no músculo esquelético durante o exercício (18-20). Igualmente, o acúmulo de G6-P proposto originalmente pelo ciclo glicose-ácido graxo tem sido questionado. Roden e cols. (20) examinaram o efeito da disponibilidade elevada de ácidos graxos na resistência à insulina em músculo esquelético. Os autores demonstraram que a redução da captação de glicose foi acompanhada de um conteúdo de G6-P reduzido. Esses achados são consistentes com as observações em pacientes diabéticos tipo 2 (19). Apesar das discrepâncias entre os estudos mais recentes e os achados de Randle e cols. (1), há consenso do efeito inibitório da disponibilidade elevada de ácidos graxos no metabolismo de glicose.

A prova de maratona é um modelo clássico de representação da importância do ciclo glicose-ácido gra-

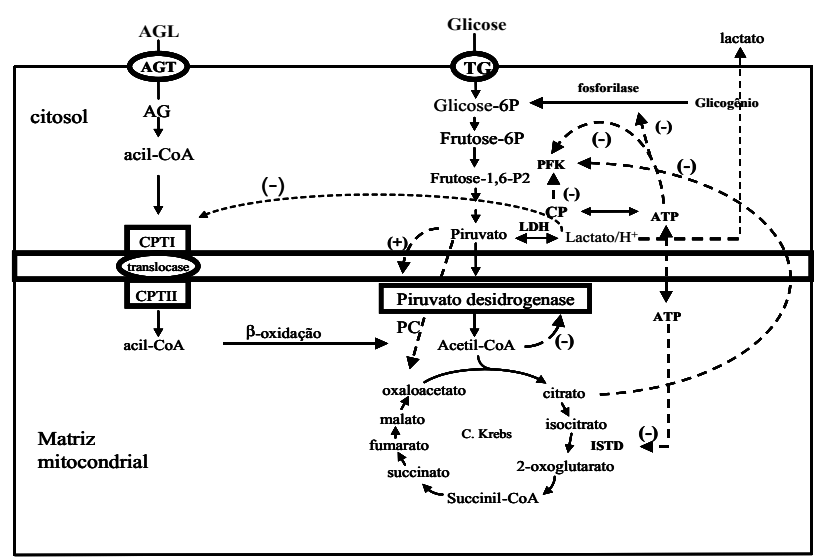

Figura 3. Efeito do ciclo glicose-ácido graxo na redução do metabolismo de glicose. AGL: ácido graxo livre; TAG: transportador de ácidos graxos; TG: transportador de glicose; HK: hexoquinase; PFK: fosfofrutoquinase; CPT: carnitina palmitoiltransferase; PDH: piruvato desidrogenase (1). xo no músculo esquelético em atividade. Embora não seja novidade, maratonistas possuem um excepcional $\mathrm{VO}_{2 \text { max }}$ variando entre 70 e $85 \mathrm{~mL} \cdot \mathrm{kg}^{-1} \cdot \mathrm{min}^{-1}$. Curiosamente, esses atletas percorrem uma maratona em intensidades abaixo do $\mathrm{VO}_{2 \text { máx }}$, como observado em eventos de duração superior a 10-15 min. A estimativa é de que muitos dos $42 \mathrm{~km}$ de uma maratona sejam percorridos em aproximadamente $75 \%-85 \%$ do $\mathrm{VO}_{2 \max }$. Desse total, $10 \mathrm{~km}$ são percorridos entre $90 \%-100 \%$ do $\mathrm{VO}_{2 \text { max }}$ e aproximadamente $5 \mathrm{~km}$, muito próximos do $\mathrm{VO}_{2 \text { max }}(2 \mathrm{l})$. Embora $15 \mathrm{~km}$ sejam percorridos de forma intensa, a maioria do percurso é realizada em intensidades abaixo do $\mathrm{VO}_{2 \max }$, sugerindo a participação do ciclo glicose-ácido graxo. Durante esse tipo de evento, a oxidação de glicose e ácidos graxos é estimada para ocorrer numa razão de 7:3; para cada sete moléculas de glicose três moléculas de ácido graxo são oxidadas (2). Nessas condições, a oxidação de lipídios favorece a continuidade da atividade muscular por longo período. Caso isso não ocorra, os estoques de glicogênio são rapidamente depletados comprometendo a continuidade da atividade. Em 1925, Hill (22) observou, pela primeira vez, a relação inversa entre distância percorrida e velocidade, o que mais tarde foi descrito por Costill (23) como relação inversa entre distância percorrida e concentração de lactato sanguíneo. Embora aparentemente simples, esses achados refletem a importância do ciclo glicose-ácido graxo durante atividades de longa duração. Porém, é importante observar que a taxa relativa de oxidação de glicose é 2,3 vezes maior (7:3) que a de lipídio, demonstrando a importância da entrada de carbonos no ciclo do ácido tricarboxílico (anaplerose) à custa de carboidrato. Geralmente, esse aumento ocorre na forma de oxalacetato, $\alpha$-cetoglutarato e malato, consequentemente aumentando a síntese de energia oxidativa (24), o que explica os $15 \mathrm{~km}$ realizados de forma intensa. Atletas de elite (nível olímpico) podem alcançar uma razão ainda maior entre carboidrato/lipídio, isto é, usam predominantemente carboidratos durante o exercício de longa duração, como demonstrado pelo quociente respiratório $(\mathrm{QR})(25)$. Esses atletas conseguem manter-se em intensidades próximas de $90 \%$ do $\mathrm{VO}_{2 \text { maxx }}$, confirmando a predominância da utilização de carboidratos (25). Nesse caso, terão maior sucesso em provas de maratona aqueles atletas que conseguirem manter uma elevada taxa de oxidação de glicose por unidade de tempo (potência aeróbia). Um quadro semelhante ao que é esperado em provas de menor duração (meia-maratona e corridas de 10.000 a $15.000 \mathrm{~m}$ ). 
Quando comparados os recordes mundiais em provas masculinas de maratona $(42,2 \mathrm{~km}$ em 02:04:55s) e meia-maratona $(21,1 \mathrm{~km}$ em 00:58:55s), observamos uma velocidade de 5,63 e $5,96 \mathrm{~m} / \mathrm{s}$, respectivamente. Uma diferença de apenas $6 \%$ sugerindo que um $\mathrm{VO}_{2 \text { máx }}$ elevado pode ser determinante na manutenção da taxa elevada de oxidação de carboidrato durante uma maratona. No entanto, uma alta capacidade de estocar glicogênio associada a uma elevada eficiência mecânica é decisiva para a performance desses atletas $(21,25)$.

A capacidade do músculo esquelético em sustentar a produção de energia oxidativa é altamente dependente da atividade mitocondrial. Fink e cols. (26) demonstraram que a atividade máxima da enzima succinato desidrogenase $(\mathrm{SDH})$ determinada em músculo gastrocnêmio de maratonistas de elite foi substancialmente maior quando comparada a de atletas de meia-distância e destreinados $(21,6 ; 17,7$ e $6,4 \mu \mathrm{mol} / \mu \mathrm{g}$, respectivamente). As consequências fisiológicas dessas alterações podem estar associadas a maior $\mathrm{VO}_{2}$, maior oxidação de lipídios, redução da glicogenólise, aumento na capacidade de manter a produção de lactato em estado estável e aumento na capacidade de sustentar a produção de energia oxidativa (resistência aeróbia) (27).

Uma possível explicação para esse fenômeno seria o maior volume de treinamento realizado por esses atletas de fundo, 161 comparado a $121 \mathrm{~km} / \mathrm{semana}$ em atletas de meia-distância (26). Esse mecanismo é facilmente percebido quando comparamos a oxidação de lipídios e carboidratos em indivíduos sedentários e atletas. Indivíduos sedentários dependem predominantemente de carboidratos durante a realização de atividade física moderada. Há também uma capacidade reduzida de realizar exercício de longa duração, ao passo que, em atletas, a predominância é dos lipídios, favorecendo a produção de energia oxidativa e a economia na utilização dos carboidratos. Nesses atletas, entre outras adaptações, ocorre aumento de biogênese mitocondrial, da densidade vascular e da atividade de enzimas oxidativas (11). Portanto, o favorecimento da oxidação de lipídios e redução na oxidação de carboidratos imposta pelo ciclo glicose-ácido graxo explica o aumento da capacidade do músculo esquelético em sustentar atividade muscular prolongada.

\section{O CICLO GLICOSE-ÁCIDO GRAXO DURANTE ATIVIDADE MUSCULAR INTENSA}

Ao contrário do exercício moderado, durante o exercício intenso ( $>65 \%-75 \% \mathrm{VO}_{2 \max }$ ), a energia requerida para suprir a demanda metabólica é preferencialmente mantida pela oxidação de carboidratos. Nessas condições, as concentrações de ácidos graxos plasmáticos são baixas sugerindo que o turnover (liberação/oxidação) deve ser alto nos adipócitos. Porém, parte dos ácidos graxos liberados pela lipólise não é direcionada para oxidação no músculo esquelético, provavelmente em decorrência da reesterificação ou limitação em alguma etapa do transporte de ácidos graxos em direção à oxidação, incluindo alteração do equilíbrio ácido-base intracelular $(\mathrm{pH})$, modulação alostérica e aumento da produção de espécies reativas de oxigênio (4-6).

Romijn e cols. (16), comparando o efeito de diferentes intensidades de esforço na lipólise, curiosamente observaram que, apesar de uma menor concentração de AGL durante a atividade muscular intensa, após o término do exercício a $85 \%$ do $\mathrm{VO}_{2 \text { máx }}$, a lipólise aumenta abruptamente e, em menor proporção, nas intensidades de $65 \%$ e $25 \%$ do $\mathrm{VO}_{2 \text { max }}$. Esse aumento não foi associado ao aumento da lipólise após o exercício, mas sim a uma maior liberação dos AGL do tecido adiposo. Durante o exercício intenso, há forte vasoconstrição periférica imposta pela maior ativação do sistema nervoso simpático, consequentemente aumentando a vasoconstrição periférica e dificultando a liberação dos ácidos graxos para a circulação sistêmica. Isso sugere que a disponibilidade limitada de ácidos graxos, durante a atividade muscular intensa, previne o aumento e a oxidação dos ácidos graxos plasmáticos, reduzindo sua taxa de oxidação (7). Interessantemente, quando a disponibilidade de ácidos graxos foi mantida artificialmente pela infusão de ácidos graxos de cadeia longa durante o exercício intenso, sua oxidação foi menor quando comparada com a oxidação de ácidos graxos durante o exercício moderado e de baixa intensidade (16). O ciclo glicose-ácido graxo, portanto, pode explicar a interação entre lipídio e carboidrato durante contrações musculares de intensidade leve e moderada, mas não durante contrações intensas. Portanto, é improvável que um aumento nas concentrações plasmáticas de AGL durante contrações intensas possa induzir uma maior preferência na oxidação de lipídios. Embora o mecanismo permaneça desconhecido, esse aparente efeito dominante da intensidade sobre a disponibilidade de substrato parece exercer papel central na escolha de carboidrato como substrato preferencial para o músculo esquelético durante contrações intensas. Então, mesmo que virtualmente exposto a ambos os substratos, durante contrações intensas, o músculo esquelético oxida preferencialmente carboidrato, 
aumentando a eficiência da contração (6). Em acordo com essa afirmação, Willis e Jackman (28) examinaram a taxa de produção de ATP em mitocôndrias isoladas de músculo esquelético humano sob estado respiratório 3. Os autores demonstraram que a taxa de produção de ATP mitocondrial na presença de ácidos graxos foi estimada para ser da ordem de três vezes menor que nas mesmas condições na presença de carboidratos. Esses achados explicam a existência de uma taxa relativa elevada de oxidação de carboidratos durante o exercício de longa duração em atletas (2).

O mecanismo que regula a preferência do músculo esquelético pelos carboidratos durante o exercício intenso ainda é desconhecido. A hipótese mais aceita é de que o efeito inibitório dos ácidos graxos na oxidação de carboidrato é removido quando a demanda energética no músculo em atividade excede aquela que pode ser sustentada pela oxidação dos ácidos graxos $(4,5)$. $\mathrm{O}$ efeito inibitório dos ácidos graxos na oxidação dos carboidratos descrito pelo ciclo glicose-ácido graxo é mediado diretamente pelo acúmulo de citrato, o qual reduz o fluxo pela via glicolítica pela inibição alostérica da enzima PFK. O citrato exerce esse efeito em combinação com ATP, um potente inibidor da PFK. Porém, durante contrações musculares intensas, um aumento no conteúdo de AMP, ADP, $\mathrm{NH}_{4}^{+}$e Pi é sempre observado $(1,2)$. Ao contrário do ATP, esses metabólitos são potentes ativadores da PFK. Sob essas condições, a razão ATP/ADP é baixa, removendo o efeito inibitório do citrato na PFK e favorecendo o fluxo glicolítico (2). Nosso grupo recentemente mostrou em cultura de células-tronco de músculo esquelético de ratos durante contrações basais (repouso) e intensas que o desacoplamento mitocondrial, uma condição conhecida de redução no conteúdo de ATP mitocondrial, significativamente aumentou a glicólise anaeróbia como demonstrado pelo conteúdo elevado de lactato no meio de cultura. Isso sugere que a razão ATP/ADP é também um regulador importante da predominância na utilização entre carboidratos e ácidos graxos no músculo esquelético durante contrações intensas (6).

A taxa de oxidação de carboidrato é outro regulador da oxidação de lipídio no músculo esquelético. Em condições basais de disponibilidade elevada de carboidrato (pós-prandial), os níveis plasmáticos de ácidos graxos circulantes diminuem devido a uma redução na lipólise imposta pela elevada produção de insulina circulante e aumento na captação hepática de ácidos graxos. Essas alterações são de grande relevância na regulação da glice- mia basal, induzindo menor oxidação dos ácidos graxos e favorecendo o aumento na taxa de oxidação da glicose. Coyle (7) testou a hipótese de que a oxidação de lipídio é regulada pelo metabolismo de carboidrato em seis ciclistas, os quais ingeriram carboidrato antes do exercício para induzir hiperglicemia e hiperinsulinemia, requiridos para aumentar o fluxo glicolítico. A taxa de oxidação de lipídio foi medida pela constante infusão de ácido graxo de cadeia longa (AGCL) marcado $\left(1-{ }^{13} \mathrm{C}\right.$-palmitato) versus ácido graxo de cadeia média (AGCM) marcado ( $1-{ }^{13} \mathrm{C}$-octanoato). Os achados mostraram que o aumento da concentração de glicose reduziu a oxidação de palmitato, sem efeito na oxidação do octanoato. A oxidação reduzida dos ácidos graxos de cadeia longa parece estar relacionada com a ativação da acetil-CoA carboxilase (ACC) seguida pela formação de malonil-CoA, o qual tem sido descrito como um inibidor do sistema carnitina palmitoiltransferase (CPT-I), com pouco efeito no transporte dos ácidos graxos de cadeia média. Assim, é improvável que um aumento da concentração plasmática de AGL, durante contrações intensas, possa induzir uma maior preferência na oxidação de lipídios. Em adição, um maior recrutamento de fibras glicolíticas (tipo II) observado durante o exercício intenso favorece o acúmulo de lactato, um inibidor da oxidação de lipídios $(4,5)$. Essas observações sugerem que, durante contrações de intensidade leve para moderada, os ácidos graxos são mobilizados do tecido adiposo pela lipólise e utilizados pelo músculo esquelético. Em contraste, durante o exercício de alta intensidade, a liberação dos AGL do tecido adiposo é marcadamente diminuída, seguida por uma elevação na taxa de oxidação de glicose (Figura 4).

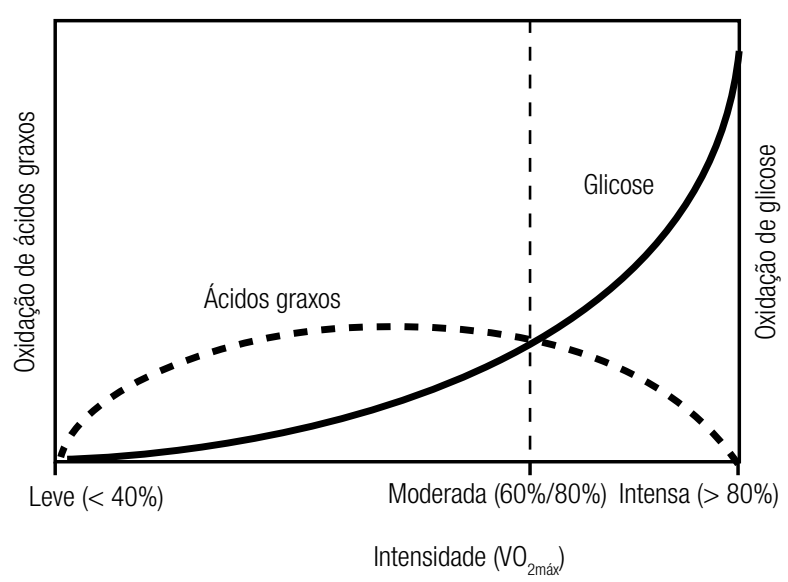

Figura 4. Efeito da intensidade de exercício no consumo de glicose e ácidos graxos. Os valores são relativos da cinética de consumo de glicose e ácidos graxos pelo músculo esquelético durante contrações. Modificado de Brooks e Mercier (29). 
Portanto, um aumento artificial na disponibilidade de lipídios plasmáticos durante a atividade muscular intensa pode conduzir a um acúmulo substancial de ácidos graxos no músculo esquelético (30).

\section{AS EROS COMO REGULADORAS DO METABOLISMO DE GLICOSE DURANTE ATIVIDADE FÍSICA INTENSA}

Nosso grupo tem mostrado que, durante a contração muscular intensa, a produção de EROs é substancialmente elevada no músculo esquelético (8), um efeito mediado pelo consumo elevado de oxigênio mitocondrial $(31,15)$. A mitocôndria, um importante sítio gerador de EROs durante a atividade muscular, pode também ser vulnerável às ações dessas espécies $(32,33)$. Em situações nas quais a produção de EROs é aumentada, o superóxido tem sido descrito, ao longo dos últimos anos, como um inibidor potente da aconitase, por um mecanismo envolvendo a oxidação do ferro, importante cofator dessa enzima (34). Embora a aconitase não seja uma enzima reguladora do ciclo de $\operatorname{Krebs}\left(\Delta \mathrm{G}^{+}\right)$, a redução na atividade dessa enzima pode resultar em menor fluxo de substratos (11). Conforme descrito anteriormente, a diminuição da atividade do ciclo de Krebs reduz a disponibilidade de agentes redutores, $\mathrm{NADH}$ e $\mathrm{FADH}_{2}$, para a cadeia de transporte de elétrons mitocondrial, comprometendo a síntese de ATP. Esse mecanismo pode favorecer a atividade glicolítica aumentando a produção de lactato $/ \mathrm{H}^{+}$e consequentemente reduzindo a oxidação de ácidos graxos $(34,35)$. Igualmente importantes ao efeito do superóxido, outras espécies, incluindo o $\mathrm{H}_{2} \mathrm{O}_{2}$, óxido nítrico e peroxinitrito, podem também inibir a atividade da aconitase (34). Um aumento nas concentrações de $\mathrm{H}_{2} \mathrm{O}_{2}$ também reduz a atividade de uma das principais enzimas reguladoras do ciclo de Krebs, a $\alpha$-cetoglutarato desidrogenase $\left(\Delta \mathrm{G}^{-}\right)$, seguido de um menor potencial de membrana $(\Delta \psi)$, como resultado da menor disponibilidade de NADH gerado pela baixa atividade do ciclo de Krebs (11,35).

Embora ainda haja poucas evidências desse mecanismo e da atividade dessas vias durante a atividade prolongada, a menor razão capacidade oxidativa/capacidade antioxidante nos músculos do tipo II (glicolíticos) sugere que a baixa capacidade antioxidante nos músculos tipo II é muito importante para o aumento da captação e oxidação de glicose durante a contração muscular intensa (Figura 5). Sandström e cols. (36),

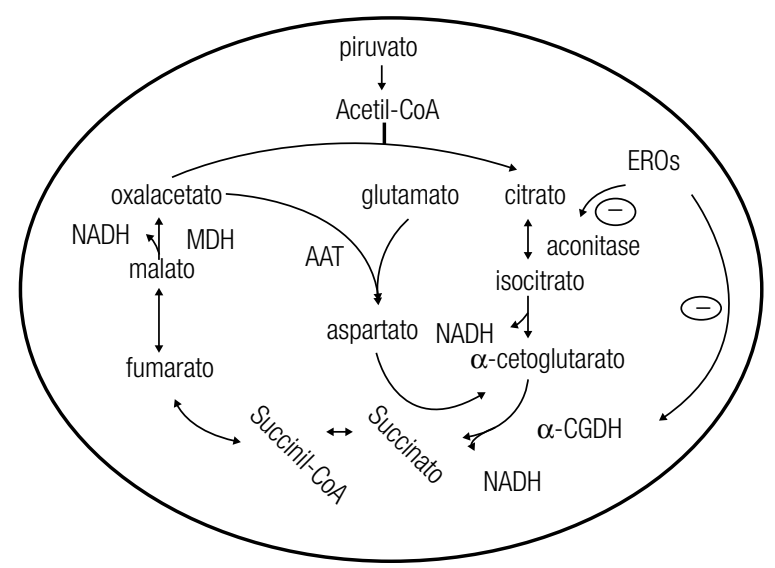

Figura 5. Efeito inibitório das espécies reativas de oxigênio na atividade da aconitase e $\alpha$-cetoglutarato desidrogenase durante a atividade muscular. AAT, aspartato aminotransferase; $\mathrm{NADH}_{+}$, nicotinamida adenina dinucleotídio reduzida; EROs, espécies reativas de oxigênio. Modificado de Silveira e cols. (24).

investigando o efeito da produção endógena de EROs na captação de glicose durante a contração muscular intensa em camundongos, demonstraram que o tratamento agudo com N-acetilcisteína (NAC), um antioxidante inespecífico e doador de GSH, reduziu a captação de glicose em aproximadamente 50\% $(\mathrm{P}<0,05)$ em comparação ao controle. Em adição, músculos de camundongos superexpressando superóxido dismutase dependente de $\mathrm{Mn}^{2+}$ (SOD- $\mathrm{Mn}^{2+}$ ), uma enzima que catalisa a conversão do ânion superóxido em $\mathrm{H}_{2} \mathrm{O}_{2}$, exibiram taxa maior de captação de glicose $(25 \%, \mathrm{P}<$ $0,05)$, durante a contração muscular, em comparação ao grupo de animais controles (wild-type). Esses resultados reforçam a proposição de que as EROs exercem efeito importante na regulação do metabolismo de glicose durante atividade muscular intensa.

\section{A PROTEÍNA DESACOPLADORA MITOCONDRIAL (UCP-3) COMO MODULADORA DO METABOLISMO DE GLICOSE E ÁCIDOS GRAXOS DURANTE A CONTRAÇÃO MUSCULAR}

A UCP-1 exerce papel importante no metabolismo energético no tecido adiposo marrom, pelo desacoplamento da respiração mitocondrial com a produção de energia, resultando em síntese reduzida de ATP $(37,38)$. Os ácidos graxos podem também induzir desacoplamento mitocondrial por um mecanismo independente de UCP $(6,39,40)$. Assim, o desacoplamento mitocondrial, como previamente reportado por um grande número de estudos, aumenta o requerimento 
de substrato energético $(6,37,41)$. Em função da homologia com a proteína desacopladora UCP-1 do tecido adiposo marrom, UCP-2 e -3 foram inicialmente descritas para exercer função importante na regulação do metabolismo, aumentando a termogênese no tecido muscular esquelético (40). Quando superexpressas em leveduras, a UCP reduz substancialmente o gradiente de $\mathrm{H}^{+}$mitocondrial $\left(\Delta \mu \mathrm{H}^{+}\right)$, confirmando o efeito termogênico (42). Porém, o mecanismo ainda permanece desconhecido. Há evidências de que as UCPs transportam $\mathrm{H}^{+}$diretamente do espaço intermembrana para a matriz mitocondrial ou ainda que o gradiente de próton $\left(\Delta \mu \mathrm{H}^{+}\right)$é reduzido pelo movimento flip-flop dos ácidos graxos, tendo como intermediária a proteína UCP, aumentando o transporte do ânion ácido graxo da matriz para o espaço intermembrana (Figura 6). Dessa forma, a UCP-3 protege as mitocôndrias contra o acúmulo de AG na matriz. Essa hipótese é suportada pelas observações de que a UCP-3 é up-regulada em situações em que a disponibilidade de AG excede sua capacidade de oxidação, incluindo jejum, dieta hiperlipídica, tratamento com hormônios tireoidianos e exercício físico agudo, ao passo que a UCP-3 é down-regulada em situações nas quais a capacidade de oxidar AG é aumentada incluindo treinamento aeróbio e redução da massa corporal (43). Em adição, a expressão elevada de UCP-3 em músculos do tipo II, comparado a músculo do tipo I, é consistente com essa hipótese, uma vez que esse tipo de músculo apresenta baixa capacidade de oxidar lipídios (44).

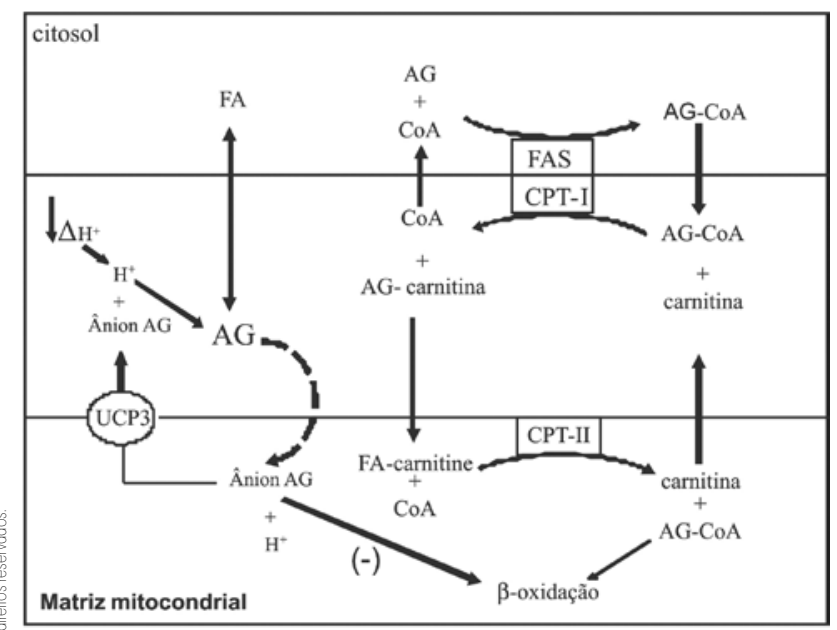

Figura 6. Mecanismo de desacoplamento mitocondrial dependente de UCP3 em músculo esquelético. CPT: carnitina palmitoiltransferase; CAT: carnitina; AG: ácido graxo; CoA: coenzima A; AG-: ânion ácido graxo; UCP3: proteína desacopladora mitocondrial. Modificado de Schrauwen e cols. (30).
Em contraste à UCP-2, expressa na maioria dos tecidos, a UCP-3 é restrita ao músculo esquelético. Desde sua descoberta em 1997 (40), uma enorme quantidade de estudos foi publicada na tentativa de caracterizar a função da proteína UCP no tecido muscular esquelético. Apesar das evidências em leveduras, experimentos utilizando camundongos knockout para o gene UCP-3 falharam em demonstrar o efeito desacoplador dessa proteína in vivo (42). Esses animais não demonstraram qualquer alteração termogênica comparados aos controles. Em adição, não apresentaram características de animais obesos, mesmo quando expostos a uma dieta rica em lipídios (42). Isso sugere que a principal função da UCP-3 em condições fisiológicas não é de proteger contra obesidade aumentando a oxidação de lipídios. Mais surpreendente é a falta de efeito da UCP-3 na performance do músculo esquelético durante a contração. Seria lógico esperar redução na disponibilidade de ATP mitocondrial em situação de elevado desacoplamento mitocondrial, uma vez que a produção de energia oxidativa é proporcionada pelo gradiente de prótons $\left(\Delta \mu \mathrm{H}^{+}\right)$. Essa energia é definida como força próton motriz $(\Delta \mathrm{P})$ consistindo de um gradiente elétrico $(\Delta \Psi)$ e químico $(\Delta \mathrm{pH}): \Delta \mathrm{P}=\Delta \Psi-59 \Delta \mathrm{pH}(38,40)$. Com base nessa teoria, a capacidade de produção final de energia será sempre maior quando o $\Delta \mathrm{P}$ for aumentado. No músculo esquelético, a eficiência máxima de utilização de ATP é somente obtida quando todos os processos de síntese estão acoplados (40). Portanto, o desacoplamento mitocondrial deve reduzir a produção oxidativa de ATP resultando em uma performance menor. Recentemente, examinando o efeito da infusão de uma solução rica em ácidos graxos de cadeia longa (lipovenos) por lh em animais experimentais, verificamos que a força de contração durante atividade muscular intensa induzida por estímulo elétrico não foi alterada em comparação à força de contração em animais controles após infusão com solução fisiológica de Krebs Ringer (6). Hesselink e cols. (45) também foram incapazes de mostrar qualquer efeito significante no torque do músculo quadríceps em humanos durante contrações máximas após tratamento com dieta hiperlipídica. A falta de efeito na performance é intrigante, uma vez que a disponibilidade elevada de ácidos graxos induz desacoplamento mitocondrial por um mecanismo intrínseco e independente de UCP-3 consequentemente reduzindo o $\Delta \mathrm{P}(6,39,40)$. Evidência desse mecanismo intrínseco foi recentemente demonstrada pelo nosso grupo em mitocôndrias isoladas de músculo esquelético de ratos na presença dos inibi- 
dores oligomicina (ATP-sintase) e carboxiatractilosídio (CAT, transportador de ATP/ADP) e ciclosporina A (poros de transição mitocondrial). A adição de lipovenos à suspensão mitocondrial aumentou significativamente o consumo de $\mathrm{O}_{2}$. Porém, GDP, um inibidor potente de UCP, não reduziu o consumo de $\mathrm{O}_{2}$ induzido por lipovenos, sugerindo que o desacoplamento foi realizado por um mecanismo independente de UCP-3. Em adição, a concentração elevada de lactato intracelular no músculo gastrocnêmio vermelho (GV) após a infusão de lipovenos sugere que muito provavelmente a glicólise anaeróbia foi muito ativada, compensando uma possível redução na síntese de energia mitocondrial. Outro aspecto importante de destacar é que a disponibilidade elevada de AG e a baixa capacidade do músculo gastrocnêmio em oxidar lipídio podem ter favorecido o acúmulo de lipídio e o desacoplamento mitocondrial, ao passo que, no músculo sóleo, a quantidade baixa de UCP-3 combinada com sua alta capacidade de oxidar FA pode ter contribuído com uma menor produção de lactato intramuscular (6). Em um experimento controle, demonstramos ainda que o tratamento de culturas de células musculares com o desacoplador mitocondrial DNP (2,4-dinitrophenol) aumentou a produção de lactato. Em outras palavras, o desacoplamento mitocondrial induzido pelo DNP diminuiu a fosforilação oxidativa aumentando a contribuição da glicólise para formação de ATP (6). Portanto, é muito provável que a atividade desacopladora mitocondrial pode levar a um aumento na oxidação de glicose seguido da inibição da oxidação de ácidos graxos.

Talbot e Brand (46) atribuíram o papel fisiológico da UCP-3 à regulação da produção de espécies reativas de oxigênio (EROs). Uma vez ativada, a UCP-3 pode aumentar o estado de oxidação da cadeia de transporte elétrons contribuindo para o aumento no estado respiratório 3 (40). Porém, evidências desse mecanismo ainda são escassas, uma vez que a ativação de UCP-3 tem falhado para induzir desacoplamento mitocondrial. Demonstramos, em cultura de células tratadas com o sistema xantina/xantina oxidase, uma fonte conhecida de geração de EROs, um aumento substancial na expressão gênica de UCP-3, sugerindo que essa proteína pode ter mesmo um papel importante na regulação da produção de EROs no tecido muscular (47). Isso seria importante para a performance muscular durante atividade intensa, uma vez que, sob elevada concentração, as EROs são importantes sinalizadores do desacoplamento mitocondrial, favorecendo a glicólise anaeróbia (6).
Portanto, durante atividade muscular intensa em que a produção de EROs é muitas vezes aumentada (8), a ativação de UCP-3 em músculos do tipo II (abundante em UCP-3) pode ser de grande importância na regulação do metabolismo de carboidrato durante contrações intensas. Embora ainda faltem evidências concretas do real papel fisiológico da UCP-3 no tecido muscular esquelético, os resultados disponíveis na literatura, incluindo achados do nosso grupo de pesquisa, sugerem que UCP-3 pode desempenhar função importante na regulação do metabolismo de lipídios/carboidratos e na produção de EROs no tecido muscular esquelético.

Em conclusão, a oxidação preferencial de ácidos graxos no estado basal e de atividade moderada muito provavelmente originou do processo de evolução biológica do homem em sobreviver e se adaptar em condições de escassez de alimento. Os estoques de carboidratos são limitados, enquanto os de lipídios são abundantes, explicando a preferência do nosso organismo pelos lipídios. A importância desse mecanismo (ciclo glicose-ácido graxo) consiste não somente no aumento de energia aos tecidos, mas ainda na economia dos estoques de glicose. Em contraste, durante o exercício de alta intensidade há predominância do metabolismo de glicose. Embora o mecanismo ainda seja desconhecido, a hipótese mais aceita é de que o efeito inibitório dos ácidos graxos na oxidação de carboidrato é removido quando a demanda energética no músculo em atividade excede aquela que pode ser sustentada pela oxidação dos ácidos graxos. Isso pode estar diretamente associado ao conteúdo elevado de AMP, $\mathrm{ADP}, \mathrm{NH}_{4}{ }^{+}$e $\mathrm{Pi}$, os quais são estimuladores da via glicolítica. A produção elevada EROs durante a atividade muscular intensa sugere que o balanço redox intracelular pode também exercer papel importante nessa regulação do metabolismo de glicose durante o exercício intenso. Esse aparente efeito dominante da intensidade sobre a disponibilidade de substrato parece exercer papel central na escolha de carboidrato como substrato preferencial para o músculo esquelético durante contrações intensas. O ciclo glicose-ácido graxo, portanto, pode explicar a interação entre lipídio e carboidrato durante contrações musculares de intensidade leve e moderada, mas não durante contrações intensas.

Agradecimentos: este estudo teve suporte financeiro da Fundação de Amparo à Pesquisa do Estado de São Paulo (Fapesp), Coordenação de Aperfeiçoamento de Pessoal de Nível Superior (Capes) e Conselho Nacional de Desenvolvimento Científico e Tecnológico $(\mathrm{CNPq})$. 
Declaração: os autores declaram não haver conflitos de interesse científico neste estudo.

\section{REFERÊNCIAS}

1. Randle PJ, Garland PB, Hales CN, Newsholme EA. The glucose fatty-acid cycle. Its role in insulin sensitivity and the metabolic disturbances of diabetes mellitus. Lancet I. 1963;13:785-9.

2. Newsholme EA. An introduction to the roles of the glucose-fatty acid cycle in sustained exercise. In: Hargreaves M, Thompson M, ed. Biochemistry of exercise IX, $185-200$. Champaign, IL: Human Kinetics; 1999, p. 119-25.

3. Hawley JA. Nutritional strategies to enhance fat oxidation during aerobic exercise. In: Burke L, Deakin V, eds. Clinical Sports Nutrition. 1994; p. 428-54.

4. Spriet LL. Regulation of skeletal muscle fat oxidation during exercise in humans. Med Sci Sports Exer. 2002;34:1477-84.

5. Hawley JA. Effect of increase fat availability on metabolism and exercise capacity. Med Sci Sports Exer. 2002;34(9):1485-91.

6. Silveira LR, Hirabara SM, Alberici LC, Lambertucci RH, Peres CM, Takahashi $\mathrm{H}$, et al. Effect of lipid infusion on metabolism and force of rat skeletal muscles during intense contractions. Cell Physiol Biochem. 2007;20:213-26.

7. Coyle EF. Fat oxidation during exercise: role of lipolysis, FFA availability, and glycolytic flux. In: Hargreaves M, Thompson M, eds. Biochemistry of exercise, vol. X. Champaign, IL: Human Kinetics, 1999, p. 263-73.

8. Silveira LR, Pereira-da-Silva L, Juel C, Hellsten Y. Formation of hydrogen peroxide and nitric oxide in rat skeletal muscle cells during contactions. Free Rad Biol Med. 2003;35:455-64.

9. Gardner PR, Fridovich I. Inactivation-reactivation of aconitase in Escherichia coli. J Biol Chem. 1992;13:8757-63.

10. Andersson $U$, Leighton B, Young ME, Blomstrand E, Newsholme EA. Inactivation of aconitase and oxoglutarate dehydrogenase in skeletal muscle in vitro by superoxide anions and/or nitric oxide. Biochem. Biophys Res Commun. 1998;249:512-6.

11. Newsholme EA, Leech AR. Biochemistry for the medical sciences. Toronto: Wiley, 1983; p. 623-7.

12. Mitchell P. Coupling of phosphorylation to electron and hydrogen transfer by a chemi-osmotic type of mechanism. Nature. 1961;191:144-8.

13. Arkinstall MJ, Tunstall RJ, Cameron-Smith D, Hawley JA. Regulation of metabolic genes in human skeletal muscle by short-term exercise and diet manipulation. Am J Physiol Endocrinol Metab. 2004;287:E25-31.

14. Kiens B, Roeman THM, Van der Vusse GJ. Muscular long-chain fatty acid content during graded exercise in humans. Am J Physiol Endocrinol Metab. 1999;276:E352-7.

15. Hirabara SM, Silveira LR, Sabdulkader F, Alberici LC, Procópio J, Carvalho CRO, et al. Role of fatty acids in the transition from anaerobic to aerobic metabolism in skeletal muscle during exercise. Cell Biochem Funct. 2006;24:475-81.

16. Romijn JA, Coyle EF, Sidossis LS, Gastaldelli A, Horowitz JF, Endert $E$, et al. Regulation of endogenous fat and carbohydrate metabolism in relation to exercise intensity and duration. Am J Physiol Endocrinol Metab. 1993;265:E380-91.

17. Costill DL, Jansson E, Gollnick PD, Saltin B. Glycogen utilization in leg muscles of men during level and uphill running. Acta Physiol Scand. 1977; $91: 475-81$.

18. Lawrence L, Dyck DJ. The glucose-fatty acid cycle in skeletal muscle at rest and during exercise. In: Maughan RJ, Shirreffs SM, eds. Biochemistry of exercise IX. p. 127-55, Champaign, IL: Human Kinetics, Scotland; 1994.
19. Savage DB, Petersen KF, Shulman GI. Disordered lipid metabolism and the pathogenesis of insulin resistance. Physiol Rev. 2007;87:507-20.

20. Roden M, Price TB, Perseghin G, Petersen KF, Rothman DL, Cline $\mathrm{GW}$, et al. Mechanism of free fatty acid-induced insulin resistance in humans. J Clin Invest. 1996;97(12):2859-65.

21. Joyner MJ, Coyle EF. Endurance exercise performance: the physiology of champions. J Physiol. 2008;586(1):35-44.

22. Hill AV. Athletic records. Lancet. 1925;5:481-6.

23. Costill DL. Metabolic responses during distance running. J Appl Physiol. 1970;28:251-5.

24. Silveira LR, Hirabara SM, Lambertucci RH, Leandro CV, Fiamoncini J, Justa-Pinheiro $\mathrm{CH}$, et al. Regulação metabólica e produção de espécies reativas de oxigênio durante a contração muscular: efeito do glicogênio na manutenção do estado redox intracelular. Rev Bras Med Esporte. 2008;14(1):57-63.

25. Spriet LL. Regulation of substrate use during the marathon. Sports Med. 2007;37(4-5):332-6.

26. Fink J, Costill L, Pollock L. Submaximal and maximal working capacity of elite distance runners. Part II: muscle fiber composition and enzyme activities. Ann NY Acad Sci. 1977;301:323-7.

27. Coyle EF. Physiological regulation of marathon performance. Sports Med. 2007;37:306-11.

28. Willis WT, Jackman MR. Mitochondrial function during heavy exercise. Med Sci Sports Exerc. 1994;26:1347-53.

29. Brooks GA, Mercier J. Balance of carbohydrate and lipid utilization during exercise: the "crossover" concept. J Appl Physiol. 1994;76:2253-61.

30. Schrauwen P, Saris WH, Hesselink MK. An alternative function for human uncoupling protein 3 : protection of mitochondria against accumulation of nonesterified fatty acids inside the mitochondrial matrix. FASEB J. 2001;15:2497-502.

31. Silveira LR. Considerações críticas e metodológicas na determinação de espécies reativas de oxigênio e nitrogênio em células musculares durante contrações. Arq Bras Endocrinol Metab. 2004;48:812-22.

32. Hellsten Y, Nielsen JJ, Lykkesfeldt J, Bruhn M, Silveira LR, Pilegaard $\mathrm{H}$, et al. Antioxidant supplementation enhances the exercise-induced increase in mitochondrial uncoupling protein 3 and endothelial nitric oxide synthase mRNA content in human skeletal muscle. Free Rad Biol Med. 2007;43:353-61.

33. Jackson MJ, Pye D, Palomero J. The production of reactive oxygen and nitrogen species by skeletal muscle. J Appl Physiol. 2007; 102:1664-70.

34. Andersson $U$, Leighton $B$, Young ME, Blomstrand $E$, Newsholme EA. Inactivation of aconitase and oxoglutarate dehydrogenase in skeletal muscle in vitro by superoxide anions and/or nitric oxide. Biochem Biophys Res Commun. 1998;249:512-6.

35. Tretter L, Adam-Vizi V. Inhibition of Krebs cycle enzymes by hydrogen peroxide: a key role of [alpha]-ketoglutarate dehydrogenase in limiting NADH production under oxidative stress. J Neurosci. 2000;20:8972-9.

36. Sandström ME, Zhang SJ, Bruton J, Silva JP, Reid MB, Westerblad $\mathrm{H}$, et al. Role of reactive oxygen species in contraction-mediated glucose transport in mouse skeletal muscle. J Physiol. 2006;575(1):251-62.

37. Schrauwen P, Hoeks J, Schaart G, Kornips E, Binas B, Van De Vusse $G J$, et al. Uncoupling protein 3 as a mitochondrial fatty acid anion exporter. FASEB J. 2003;17:2272-4.

38. Kadenbach B. Intrinsic and extrinsic uncoupling of oxidative phosphorylation. Biochim Biophys Acta. 2003;1604:77-94.

39. Alberici LC, Oliveira HC, Bighetti EJ, de Faria EC, Degaspari GR, Souza CT, et al. Hypertriglyceridemia increases mitochondrial resting respiration and susceptibility to permeability transition. J Bioenerg Biomembr. 2006;35:451-7. 
40. Skulachev VP. Uncoupling: new approaches to an old problem of bioenergetics. Biochim Biophys Acta. 1998;1363:100-24.

41. Hirabara SM, Silveira LR, Alberici LC, Leandro CVG, Lambertucci $\mathrm{RH}$, Polimeno GC, et al. Acute effect of fatty acids on metabolism and mitochondrial coupling in skeletal muscle. Biochim Biophys Acta. 2006;1757:57-66.

42. Vidal-Puig AJ, Grujic D, Zhang CY, Hagen T, Boss O, Ido Y, et al. Energy metabolism in uncoupling protein 3 gene knockout mice. J Biol Chem. 2000;275:16258-66.

43. Hirabara SM, Silveira LR, Abdulkader F, Carvalho CRO, Procópio J, Curi R.Time-dependent effects of fatty acids on skeletal muscle metabolism. J Cell Physiol. 2006;210:7-15.

44. Silveira LR. Determinação de espécies reativas de oxigênio e óxido nítrico através de sondas fluorescentes in vitro utilizando culturas de células musculares e músculos isolados e sua aplicação in vivo com a técnica de microdiálise. Campinas, 2003. (Tese de Doutorado - Instituto de Biologia, Universidade Estadual de Campinas).

45. Hesselink MK, Greenhaff PL, Constantin-Teodosiu D, Hultman E, Saris WH, Nieuwlaat R, et al. Increased uncoupling protein 3 content does not affect mitochondrial function in human skeletal muscle in vivo. J Clin Invest. 2003;111:479-86.

46. Talbot DA, Brand MD. Uncoupling protein 3 protects aconitase against inactivation in isolated skeletal muscle mitochondria. Biochim Biophys Acta. 2005;1709:150-6.

47. Silveira LR, Pilegaard $H$, Kushuara K, Curi R, Hellsten Y. The contraction induced increase in gene expression of peroxisome proliferator-activated receptor (PPAR)-gamma coactivator 1-alpha (PGC-1 $\alpha$ ), mitochondrial uncoupling protein 3 (UCP3) and hexokinase II (HKII) in primary rat skeletal muscle cells is dependent on reactive oxygen species. Biochi Biophys Acta. 2006;1763:969-76. 